\title{
Exploring childhood immunization uptake with first nations mothers in north-western Ontario, Canada
}

\author{
Marie Tarrant RN MN \\ of Nursing and Public Health, Edith Cowan University, Perth, Western Australia, Australia \\ David Gregory RN PhD \\ Professor and Dean, Faculty of Nursing, University of Manitoba, Winnipeg, Manitoba, Canada
}

Assistant Professor, Department of Nursing Studies, University of Hong Kong, Hong Kong, China and PhD Candidate, School

Submitted for publication 18 January 2002

Accepted for publication 25 September 2002

Correspondence:

Marie Tarrant,

Department of Nursing Studies,

Faculty of Medicine,

4/F, Academic and Administration Block, 21 Sassoon Road,

Hong Kong,

China.

E-mail:tarrantm@hkucc.hku.hk
TARRANT M. \& GREGORY D. (2002) Journal of Advanced Nursing 41(1), 1-10 Exploring childhood immunization uptake with first nations mothers in northwestern Ontario, Canada

Background. Childhood immunization is an important component of preventive health care for young children. Successful control of vaccine-preventable diseases depends on high levels of immunization coverage. Immunization statistics show that on-reserve First Nations (Native Indian) children have lower vaccination coverage than children in the general Canadian population. There has been little research, however, conducted with First Nations populations on this topic.

Aim of the study. This study explored First Nations parents' beliefs about childhood immunizations and examined factors influencing immunization uptake.

Methods. This study used a qualitative descriptive design to explore the issue of childhood immunization uptake. Twenty-eight mothers from two First Nations communities in north-western Ontario, Canada, were interviewed about their perceptions of childhood immunizations and vaccine-preventable diseases. The interviews were transcribed and content analysis was used to examine the data.

Findings. Data analysis revealed the following six themes: (1) the fear of disease, (2) the efficacy of immunizations, (3) the immunization experience, (4) the consequences of immunization, (5) interactions with health professionals, and (6) barriers to immunizations. Participants were motivated to seek immunizations for their children by a fear of vaccine preventable diseases. A small proportion of mothers, however, questioned the effectiveness of vaccines in preventing disease. Traumatic immunization experiences, vaccine side-effects and sequelae, negative interactions with health professionals, and barriers such as time constraints and childhood illnesses all served as deterrents to immunization.

Conclusions. The research outcomes highlight the varied beliefs of First Nations parents about childhood immunizations and the numerous factors that both positively and negatively influence immunization uptake. Further research is needed to explore the issue of childhood immunizations in First Nations communities and to determine strategies to improve uptake.

Keywords: Childhood immunizations; vaccinations; First Nations; uptake; qualitative research; public health nursing

\begin{tabular}{|c|l|l|l|l|l|l|l|l|l|ll|}
\hline $\mathbf{3}$ & $\mathbf{B}$ & $\mathbf{0}$ & $\mathbf{1}$ & $\mathbf{6}$ & $\mathbf{2}$ & $\mathbf{5}$ & $\mathbf{0}$ & $\mathbf{7}$ & $\mathbf{B}$ & Dispatch: 25.10 .02 & Journal: JAN \\
\cline { 2 - 3 } & \multicolumn{6}{|c|}{ Journal No. } & \multicolumn{6}{|c|}{ Manuscript No. } & Author Received: & No. of pages: 10 \\
\hline
\end{tabular}




\section{What is already known about this subject?}

- Childhood immunization uptake is adversely influenced by factors that include parental misperceptions, vaccine side-effects, negative outcomes from vaccination, and health-care system barriers.

- Since exposure to communicable diseases has declined, many parents have become more concerned about the side-effects of vaccines rather than the disease itself.

- Although First Nations children experience some of the lowest rates of vaccination coverage in Canada, little is known about First Nations parents = perceptions of childhood immunizations.

\section{What does this study add?}

- It confirms that First Nations mothers, as do parents elsewhere, hold misperceptions about which diseases are vaccine-preventable and the nature of protection provided by vaccines.

- An increased exposure to victims of vaccine-preventable diseases in the study population did reinforce the importance of vaccinations with some First Nations mothers.

- Higher rates of infectious diseases and minor childhood illnesses in First Nations children highlight the importance of education to First Nations parents about the true nature protection offered by vaccines and of provider adherence to valid contraindications to vaccination.

\section{Introduction}

The development of vaccines is considered one of the greatest achievements of biomedical science and public health (Centers for Disease Control and Prevention 1999b). Consequently, immunizing children has been a cornerstone of public health practice for the better part of the 20th century. Since their introduction, vaccines have been responsible for a dramatic decline in the incidence of diseases such as measles, rubella, pertussis, tetanus, diphtheria, and Haemophilus influenzae type b. Despite the success of vaccines in reducing the morbidity and mortality associated with vaccine-preventable diseases, there are still large segments of the population inadequately immunized. Consequently, in recent years there have been outbreaks of communicable diseases in Canada and the United States of America (USA) in underimmunized or nonimmunized groups (Hutchins et al. 1989, Bruneau \& Duchesne 2000).

\section{Background}

In Canada, one group vulnerable to vaccine-preventable disease outbreaks is First Nations children. First Nations, or Native Indian people, live on lands called 'reserves', which have been allocated to them by the Government of Canada as part of the Indian Act of 1876 (First Nations and Inuit Health Programs 1999). Many of these reserves are in isolated and remote areas of northern Canada. The First Nations population is younger than the general Canadian population. Birth rates are double the national rate and $35 \%$ of the population is $<15$ years of age compared with $20 \%$ in the general population (Statistics Canada 1996). First Nations people also experience lower incomes, poorer housing, higher infant mortality rates, and higher rates of infectious diseases than do mainstream Canadians (First Nations and Inuit Health Programs 1999). Immunization data show that on-reserve First Nations children have lower vaccination coverage than children in the general Canadian population. The percentage of 2-year-old-on-reserve First Nations children who had obtained the 18-month diphtheria, pertussis, tetanus, and polio vaccine in 1997 ranged from $49 \%$ in Alberta to $83 \%$ in British Columbia (First Nations and Inuit Health Programs 1999). In Ontario, the coverage rate for this vaccine was $59 \%$, well below the national target of $95 \%$ (National Advisory Committee on Immunization 1997).

In north-western Ontario, a vast geographical region that stretches from the Manitoba border to the shores of the Hudson Bay, First Nations people live on remote and isolated reserves dispersed across the region. Many communities are accessible only by air. Nurses, functioning in an expanded-practice role, provide health care services through outpost nursing stations and community health clinics. Substandard living conditions on reserves, combined with the higher rates of infectious diseases, high birth rates, and low childhood immunization rates, significantly increases the vulnerability of this population to disease outbreaks. Increasing immunization rates in this population is important to prevent future outbreaks and to reduce morbidity from vaccine-preventable diseases. To improve immunization rates, research was necessary to provide a better understanding of the perceptions of childhood immunizations held by First Nations parents and the many factors that influence uptake. 


\section{The study}

\section{Aim}

The purpose of this study was to explore First Nations parents' beliefs about childhood immunizations and to examine factors influencing immunization uptake.

\section{Method}

\section{Research design}

This study used a qualitative descriptive design to explore the issue of childhood immunization uptake. This design was selected because it presents a comprehensive summary of an event or experience in everyday terms, and is the preferred method when the aim of the researcher is to obtain straight answers to questions of special relevance to practitioners (Sandelowski 2000).

\section{Instrument}

An interview guide, with open-ended questions, was developed for the study by the first author (see Table 1). The interview questions were generated from numerous published studies on parents' experiences with and perceptions of childhood immunizations extracted from the Medline and CINAHL databases. Resources describing the historical experiences of First Nations people provided context for the interview questions (Young 1979, 1988, 1990, 1994). To ensure content validity, the interview guide was reviewed by two graduate level public health professionals experienced in working with First Nations populations. The open-ended

Table 1 Sample questions from interview guide

1. When I say the word 'immunization', what are some thoughts that come to your mind?

2. Tell me about some of the good things that you think your child gets from immunizations

3. Tell me about some of the bad things about immunizations

4. Tell me about some of the diseases that you think immunizations prevent or can protect your child from

Probes: Seriousness of diseases? Knowledge of people who have had the diseases? Experiences with outbreaks of diseases?

5. Tell me about what usually happens when you take your child to the clinic for an immunization

Probes: Best experience? Worst experience?

6. Can you tell me some stories that you have heard about immunizations from family and friends or other community members?

Probes: Diseases or epidemics that occurred? Stories of negative consequences of immunization? Other parents' attitudes toward vaccination? questions in the interview guide provided a flexible framework for the interviews where participants were encouraged to discuss any issue they deemed relevant to the topic of childhood immunizations. Prompts and probes were used to encourage further discussion of the participants' beliefs and experiences.

\section{Sample selection}

Research participants were parents of young children from two First Nations communities in north-western Ontario. For study purposes, 'parent' was defined as the person, regardless of gender or actual biological relationship, who was responsible for the direct care of the identified child. Ultimately, all study participants were female and the biological mothers of the identified children. A purposeful sample selection technique was used and selection criteria for the study participants included: First Nations person; 18 years of age or over; caring for at least one child less than 5 years of age; English speaking; currently residing in the community; and willing to engage in the study. The goal of sample selection was to identify participants knowledgeable about the topic under study. Therefore, caring for a child less than 5 years of age was chosen as a selection criterion in order that participants would have recent exposure to childhood immunizations and be better able to recall their experiences. Because of study constraints, subjects were limited to those who spoke English. In both participating communities, however, English is spoken fluently by people $<50$ years of age, thus making it unlikely that this restriction eliminated a large number of potential participants.

\section{Data collection}

Birth records from the past 5 years were accessed to identify possible participants. The local Community Health Representative assisted the researcher in identifying and contacting potential participants who would be knowledgeable about the research topic and who would be willing to take part in the research. Over the period of data collection, a total of 49 mothers were contacted and invited to participate in the study. Fourteen people declined to participate and a further seven initially agreed but subsequently changed their minds. The reason most commonly given for nonparticipation was time constraints. Semi-structured person-centred interviews (Levy \& Hollan 1998) were conducted with 28 mothers. Interviews were scheduled at the participants' convenience and at a location suitable to them, usually in a private room in the community health clinic or in their home. After obtaining informed consent, all interviews were carried out by the first author. Sampling continued until the data were rich, saturated, and accurately 
described the participants' experiences. The interviews, conducted in English, lasted from 30 to 90 minutes and with the participants' permission, were tape recorded. The tapes were later transcribed verbatim by a trained transcriptionist and were validated by the first author.

Basic demographic data were collected from all participants, including the immunization status of any children $<5$ years of age. Initially, it was intended to compare the interview responses of those participants whose children were age-appropriately immunized to those whose children were not age-appropriately immunized. Children are considered age-appropriately immunized if all vaccines are administered at the recommended age or within a 30-day grace period (Dietz et al. 1993). Because none of the participants in the study had children who met these strict criteria, the grace period was lengthened to 60 days. However, even then, only a small number of participants $(n=7)$ had children who were age-appropriately immunized and no differences in the response patterns between the two groups could be discerned.

\section{Data analysis}

With qualitative research, data collection and data analysis are simultaneous processes. Both data collection and data analysis require a fluid, flexible, and iterative interaction between the researcher and the data (Brink 1989). After each interview, the taped interviews were replayed, key ideas and concepts were identified, and in-depth field notes were written. During formal data analysis, content analysis was employed following the guidelines put forth by Morse and Field (1995). Content analysis is the analysis strategy of choice in qualitative descriptive studies (Sandelowski 2000) and involves categorizing the content of the data and assigning code labels to those categories (Morse \& Field 1995). During this phase of data analysis, often referred to as 'open coding', categories were freely generated and accounted for all of the meaningful interview data (Burnard 1991). Similar categories were grouped under larger broad categories and core themes were identified. Finally, the transcripts were read again to validate the codes and categories and to ensure that all data were coded.

A manual method of data management using a word processing programme was used to assist with data analysis. Webb (1999) recommends this manual method of data management in qualitative research projects with fewer than 30 subjects in order to give the researcher a greater familiarity and intimacy with the data and to enhance data analysis.

\section{Qualitative rigour}

Methodological rigour was established, in part, using guidelines set forth by Guba and Lincoln (1989) to establish trustworthiness. These criteria include credibility, transferability, dependability, and confirmability (Lincoln \& Guba 1985, Sandelowski 1986). Credibility was enhanced throughout the data collection phase by repeated validation of emerging themes in succeeding interviews and by ongoing debriefing between the two researchers during data collection and the analysis process. In addition, at the end of each interview, the researcher summarized the interview and validated the interview data with the participants. Transferability was addressed by providing clear descriptions of the sample and data collection procedure, as well as providing textual excerpts directly from the interview transcripts. Dependability was achieved through the detailed and clear description of the study from problem identification through data analysis and discussion. To establish confirmability, participants' own words were used to substantiate the interpretations of the data.

\section{Ethical considerations}

Before the study commenced, measures were implemented to ensure that the rights of the participants would be protected. Ethical approval was obtained from the ethical review committee of the supervising academic institution and from the research review committee of the local health department. A letter was also sent to the leaders of both communities explaining the research and requesting permission to conduct the study. All participants were provided with a clear written and verbal explanation of the research study. Informed consent was obtained from each participant along with assurances of confidentiality and anonymity.

\section{Findings}

The demographic profile of the participants is presented in Table 2. Analysis of the data revealed six themes related to the uptake of childhood immunizations:

- The fear of disease.

- Efficacy of immunizations.

- The immunization experience.

- Consequences of immunization.

- Interactions with health professionals.

- Barriers to immunizations.

\section{The fear of disease}

When asked about the benefits of immunization, prevention of childhood disease was mentioned most frequently by the mothers. Half of the participants $(n=14)$ stated that the fear of the potential consequences of vaccine-preventable diseases, 
Table 2 Demographic profile of participants

\begin{tabular}{ll}
\hline Age of participants & \\
Range (years) & $18-41$ \\
Mean & $28 \cdot 19$ (sD $=5 \cdot 38)$ \\
Number of children & \\
Range & $1-8$ \\
Median & 3 \\
Highest level of education & $\%(n)$ \\
Kindergarten to Grade 8 (primary) & $36(10)$ \\
Grade 9 to 12 (secondary) & $53(15)$ \\
Completed secondary school & $7(2)$ \\
Some College or University & $4(1)$ \\
Employment status & $\%(n)$ \\
Full-time & $36(10)$ \\
Part-time & $14(4)$ \\
Not employed & $50(14)$ \\
Marital status & $\%(n)$ \\
Married & $61(17)$ \\
Common-law & $25(7)$ \\
Not married & $14(4)$ \\
\hline
\end{tabular}

such as permanent disability or death, was the primary motivating factor in seeking immunization services. These mothers believed that if immunizations prevented these diseases, it was their responsibility as a parent to ensure that their children were appropriately immunized. One mother commented:

I wouldn't want my child to have any of those diseases that were here a long time ago...it sounds horrible...They just scare me...So I just bring them in whenever they have to get it. I just think it's just what they need. to prevent the diseases.

Knowing sufferers of vaccine-preventable diseases also reinforced this fear and provided further incentive for mothers to immunize their children:

There's a guy in town who's in a wheelchair because of polio... When I see that person I know they never had that choice, or it was too late for him cause he couldn't be helped here. Right now we have this chance to have this medical help so I try and bring my kids in.

\section{Efficacy of immunizations}

The role of vaccines in preventing disease was explored with participants. Mothers had mixed opinions and not all were convinced that immunizations were effective. The majority of mothers $(n=25)$ believed that having their children immunized prevented them from becoming ill and thus viewed immunizations as effective in preventing disease. Four participants, whose children were frequently sick and behind on their immunizations, stated that their children experienced fewer minor illnesses, such as colds and flu, once they had all of their immunizations. However, three mothers stated that they did not believe that immunizations had any impact on their children's health. These mothers observed that their children suffered from many infections despite being immunized and thus they did not see the benefit of ongoing immunizations. One of these three participants stated:

I think, whether or not they're getting needles, they still get sick. They still get sick. They still get sick a lot as much as the nurses say they won't...I don't think it prevents anything... They get colds every year and during the winter months they miss, they miss a lot of school because of their colds.

Participants were confused about the efficacy of immunizations and cited examples of children contracting measles and whooping cough despite being immunized. One mother, echoing the concerns of other mothers, questioned why this occurred:

Even if they are immunized, there are some that catch it. Like they're asking why their children get whooping cough even though they had been immunized for it. I wonder, I was questioning that too.

\section{The immunization experience}

Mothers stated unanimously that having their children immunized was something that they did not enjoy. Their children cried from the needles and some mothers did not want to be in the same room when the needle was given. Three mothers recalled situations when they had brought their children to the nursing station and became upset and distressed with what occurred. These negative experiences strongly influenced how these mothers felt about immunizing their children. One of the three mothers described her experience:

One time when the nurse was there I was holding her [child] and I guess I wasn't holding her enough to keep her still. and she [the nurse] poked her once and she moved and it squirted all over her legs. She poked her two or three times before she could get it. She had to call another nurse to help her and that other nurse, she was holding her so hard her knuckles turned white. and that made me feel so bad. She ended up having bruises on her thighs and fingerprints on her arm from that nurse.

The vaccination process was also a deterrent to parents with older children. These children developed a fear of needles as a result of their previous immunizations and now loudly 
protested when they had to be vaccinated. This behaviour embarrassed their mothers and often made them dread bringing their children to the clinic:

My son...I didn't want to bring him...cause I just didn't like the way he acted every time I brought him here. Like I just didn't like the way he was screaming over nothing...Well, I think it's the needles...He just wanted to get out of there, away, he was pulling me and I couldn't talk, like the nurse was trying to talk to me but I couldn't even talk.

\section{Consequences of immunization}

When questioned about the negative consequences of immunizations, mothers mentioned stories that circulated in their communities about immunizations sometimes causing serious illness and even death in children. These stories reinforced anti-immunization sentiments in the community and increased some parents' suspicions about immunizations. While participants stated that these stories did not influence their perceptions of immunizations, all agreed that the stories often influenced others and contributed to a general antiimmunization attitude in the community for an extended period of time after the precipitating event. For example, one participant remarked:

[I] remember what happened to that child, he had an immunization needle the day before he went into seizures and he died...I heard people say that he had received a needle and that probably was the cause of it.

Another consequence of immunization mentioned by 20 of the mothers was the occurrence of vaccine side-effects. These participants all stated that their children usually suffered from mild side-effects after vaccination. Side-effects, such as fever and irritability, were commonly reported as lasting for a day or two. Although participants understood the side-effects were short-term and that the long-term benefits of immunizations were more important, three mothers did admit to a reluctance in returning for further immunizations. One of the three commented:

They get fevers and then sometimes they throw up. [My son] he gets fevers, really high fevers. and then he would, he wouldn't sleep at all. He wouldn't roll on his side. He was just cranky all night, until the morning. It made me not want to come back. But I had to for his benefit.

\section{Interactions with health professionals}

All mothers were encouraged by health professionals, primarily nurses at the nursing station, to immunize their children. Participants usually received helpful information about immunizations and childhood diseases from health professionals and spoke of the importance of having positive interactions with them. Ten mothers stated that nurses should listen to them more during clinic visits and take an interest in the mother and baby. One mother emphasized that nurses must do more than just administer a needle:

It's just nicer to have a nurse who seems caring for the baby, who seems really interested in knowing how you guys are doing. There should be more questions of that nature. Just a few questions and so forth and then I get examination, needle, and then I get thrown out. It's just nice to have a, like chat with the mother and to get calm and all that.

Participants' beliefs about childhood immunizations were often influenced by negative interactions with health professionals at immunization or nonimmunization visits. Eleven participants reported that they were scolded and reprimanded by health professionals over issues related to childcare, treatment of their children's illnesses, and even their frequent visits to the clinic. These reprimands upset the mothers and left them feeling inadequate about their child rearing capabilities. Participants also stated that as a consequence of these negative interactions, they did not return to the clinic for a long time so as to avoid seeing that certain health professional.

\section{Barriers to immunization}

Mothers identified factors that made it more difficult for them to maintain their children's immunization schedule. They noted time constraints, clinic factors, and childhood illnesses as barriers to immunization.

\section{Time constraints}

Mothers found that other demands on their time sometimes made it difficult for them to come to the clinic for immunization. Accessing immunization services was problematic for mothers who had other children. Participants who were not employed outside the home reported greater difficulty in bringing their children to the clinic for immunizations. All but two participants had more than one child and found it was often impossible to obtain a babysitter for the other children. Without a babysitter, the women had to consider bringing all their children to the clinic. Working mothers had childcare arrangements in place and therefore found it easier to bring their children to the clinic when required. The majority of working mothers $(n=11)$ reported that it was usually not difficult to leave work for a short period to have their children immunized. 


\section{Waiting time}

Long clinic waiting times were identified by 17 participants as a major barrier to immunization. Participants often had to wait for up to an hour in the clinic and believed that this was too long. Others complained that although they were given appointments they were not seen at the scheduled time. The extended waiting time upset some of the participants to the extent that they left the clinic before being seen:

When we phone to make an appointment. at 2:30, and then we come here at 2:30 and we sit here until 3:15 in the waiting room. They specifically said that your appointment is at 2:30 but you have to wait another 30 or 45 minutes.

Although working mothers found it easier than nonworking mothers to bring their children to the clinic, they were more bothered by having to wait. One participant who was employed full-time stated:

Like if I have a really busy day at work, I can't wait more than half an hour. The other times I don't mind waiting. I enjoy having the other kids play with them. I feel I get to talk to people more, the ones who are waiting. I really don't mind waiting that long but it depends on which day it is.

\section{Illness}

Almost half of the participants $(n=12)$ reported that when their children were due for immunizations they were frequently ill. Consequently, the mothers would not bring them to the clinic for their scheduled immunization and instead would wait until the child was well. A participant whose child was frequently ill described what would often happen:

When Thursday came around if she'd have a runny nose and things like that, I would just call and tell them that I can't make it and I would come next week. I'd just call them and let them know she's sick or I'll bring them in for a check up and they'd tell me she's sick.

Participants stated that nurses were often reluctant to immunize their child during an illness, and they themselves also preferred to wait until the child was well out of fear that the immunization would make their ill child feel worse. Fever was cited as the deciding factor by 10 of these participants; they did not want their febrile child immunized. Because of frequent illness and the hesitancy of parents and nurses to immunize children during an illness, children often fell behind on their immunizations. Mothers whose children had repeated ear and respiratory infections found that the children were ill so often that there was rarely a time they were well enough to be immunized. One of these mothers lamented:
The only time I bring them is when they're sick...and then when I'm reminded again, usually they're not feeling well and it just keeps going on.

\section{Discussion}

Findings from this study share some similarities with previously published studies (Bennett \& Smith 1992, Keane et al. 1993, White \& Thomson 1995). At the same time, the results offer insight into the unique challenges of providing childhood immunization services to First Nations populations.

\section{Vaccine-preventable diseases}

A key factor identified by mothers which encouraged immunization uptake was the fear of vaccine-preventable diseases. Some mothers related stories of knowing victims of polio and other diseases and how this reinforced the importance of immunization. conversely White and Thomson (1995) found that New Zealand mothers had rarely been exposed to the consequences of vaccine-preventable diseases and few could describe the nature of such diseases. Others have suggested that as parents rarely have first-hand experience with many of the vaccine-preventable diseases, fear of their children catching diseases is no longer an incentive to seek immunizations (Buchanan \& Spencer 1983, Roden 1992). The rates of many vaccine-preventable diseases, however, have historically been higher in First Nations communities (Postl \& Moffatt 1988), and it is possible that mothers in these communities have witnessed some of these diseases. For First Nations mothers, the threat of vaccinepreventable diseases may still be real and therefore an incentive to vaccinate children.

Although study participants viewed vaccines as effective in preventing childhood diseases, some questioned their efficacy when immunized children developed diseases such as pertussis and measles. Parents often feel betrayed by health professionals when vaccine-preventable diseases occur in vaccinated children (White \& Thomson 1995). Furthermore, some of the participants in this study who thought vaccines were effective cited the decrease in coughs and colds their children experienced after vaccination as evidence that vaccines were effective. It has been reported elsewhere that other parents hold similar beliefs (Keane et al. 1993). Nurses may contribute to these misconceptions by not being specific with parents about the protection offered by immunizations. Parents should be informed that no vaccine offers $100 \%$ protection from disease. It is also important that parents be 
made aware of diseases that are vaccine-preventable and, as importantly, which common illnesses are not vaccine preventable. First Nations children frequently develop coughs, colds, and otitis media (MacMillan et al. 1996), and simply advising mothers that immunizations protect children from general illness or disease can lead to misunderstanding.

\section{The health care system}

Results of this study show that the health professionals had varying impact on First Nations mothers' immunization behaviours. Mothers received positive advice and guidance on the importance of immunizing their children, yet the behaviour of the health professionals often discouraged mothers from immunizing their children. Insensitivity and poor treatment by clinic staff have been identified in other studies as an impediment to childhood immunization and preventive health services (Bennett \& Smith 1992, Houseman et al. 1997). Rural parents interviewed by Pruitt et al. (1995) reported that unsympathetic treatment by clinic staff affected their health-seeking behaviours for several years after the event. Fear of further negative encounters may cause parents to avoid seeking care until it is absolutely necessary, especially in small communities where the choice of health care providers is limited. Avoidance of the health care system restricts the extent of promotive and preventive care that can be delivered to families who are likely in the greatest need of this type of care.

1 Studies by Lannon et al. (1995), Pruitt et al. (1995), 2,3Houseman et al. (1997) and McCormick et al. (1997) have examined system barriers such as accessibility and waiting times and found that they have a negative impact upon childhood immunization uptake. In this study, accessing the clinic was a greater problem for stay-at-home mothers who had other small children and did not have childcare readily available. Although working mothers did not experience the same problem in being unable to take their children to the clinic, they did express frustration with the usual long wait. Excessive waiting time is a widespread problem in the health care system and is not limited to immunization services. Although it may be impossible to completely eliminate waiting time, health care planners and clinic managers must be more aware of the negative impact it can have. Salsberry et al. (1993) established that providers substantially underestimate the impact of system barriers such as waiting time on parents' behaviours. Morrow et al. (1998) found that children whose parents experienced long waiting times were more likely to be underimmunized and that for each additional hour the parents reported waiting, children were 1.6 times more likely to be underimmunized.

\section{Vaccine sequelae}

Results from this study suggest that adverse events following vaccination can contribute to community-wide concern about the safety of vaccines. Research studies have previously documented sharp declines in vaccination rates following widespread media reports of vaccine-induced illnesses (Gangarosa et al. 1998). Adverse reactions to vaccinations, such as seizures and respiratory distress, can have a powerful impact on people's perceptions of potential consequences of vaccination, especially in small communities where stories spread rapidly and families are closely connected. Many incidents that occur following vaccination are isolated events that would have occurred anyway. The first year of life is the busiest for immunizations and it is also the time when many diseases and developmental abnormalities first become apparent (Centers for Disease Control and Prevention 1999a). However, immunization is frequently implicated because it provides an explanation as to why a previously healthy child succumbs to an unusual illness (White \& Thomson 1995). It is natural for vaccine safety concerns to increase when the incidence of the disease falls (Chen \& DeStefano 1998), and parents can forget that the benefits of immunization outweigh the risks and consequences. Health professionals need to respond to community concerns about vaccine safety with clear, accurate information. Maintaining parental and community confidence in vaccination programmes is crucial if high levels of vaccination coverage are to be achieved.

\section{Delayed immunization}

Minor childhood illness, especially when accompanied by fever, was cited by participants as a reason for delaying their children's immunizations. These findings are consistent with those of Lannon et al. (1995) and Pruitt et al. (1995) who found that the inadvisability of immunizing a sick child was a common belief among the mothers interviewed. Other studies have revealed that up to half of parents who delayed immunization, did so because of minor illnesses that did not pose contraindications to vaccination (Loevinsohn 1989, New \& Senior 1991, Abbotts \& Osborn 1993, Salsberry et al. 1994). Health professionals are often reluctant to immunize a child who is ill and/or febrile (Salsberry et al. 1995, Weese \& Krauss 1995), and mothers are unwilling to permit such a child to be immunized. Immunizing ill children, however, does not cause a significant increase in side-effects and seroconversion rates are similar in ill and well children (Centers for Disease Control and Prevention 1999a). The National Advisory Committee on Immunization (1998) 
clearly stipulates that minor illness, such as otitis media, upper-respiratory tract infections, colds, and diarrhea, with or without fever, are not contraindications to vaccination.

These findings highlight a common misperception on behalf of both parents and providers about the true contraindications to vaccination that result in missed opportunities to vaccinate eligible children. Missed opportunities have been shown repeatedly to be one of the greatest barriers to achieving high levels of immunization coverage (Hutchins et al. 1989, McConnochie \& Roghmann 1992, Szilagyi et al. 1993, Weese \& Krauss 1995, Holt et al. 1996, Sabnis et al. 1998). The majority of immunizations delayed as a consequence of illness lack true contraindications to vaccination and substantially contribute to the under immunization of children (Klein et al. 1989, Gindler et al. 1993, Salsberry et al. 1994, Weese \& Krauss 1995). Failure to vaccinate mildly ill children, especially those who experience frequent illnesses, can result in these children being inadequately immunized for lengthy periods of time. Inadequate immunization can place children at risk of contracting vaccinepreventable diseases, the consequences of which are often life-threatening. Although parents are reluctant to have their children immunized during an illness, proper education about common vaccine side-effects and accurate information about the benefits and risks of vaccinations can help overcome this barrier (Santoli et al. 1998).

\section{Conclusion}

The outcomes of this research highlight the varied beliefs of mothers about childhood immunizations and the numerous factors that both positively and negatively influence immunization uptake. Improving education for both health care providers and parents about the appropriate contraindications to vaccination can substantially reduce missed opportunities and increase vaccination rates. Reducing waiting time and maintaining positive relationships with parents would also likely enhance immunization uptake. These results provide new information to practitioners and researchers working with First Nations people and have been shared with the leaders and health planners in the two study communities.

This research, however, was a small endeavour to examine a complex issue and findings must be interpreted cautiously. Although First Nations communities across Canada share similar experiences, they are, nonetheless, diverse communities. The purposive sampling strategy, the small sample size, and the geographical isolation of the two study communities limit the generalizability of these findings. Hence, the results from this study may not represent the experience of parents in other First Nations communities, and further research is required to better understand the barriers and facilitators of immunization uptake.

Finally, this study examined immunization uptake only from the perspective of First Nations mothers. To have a more complete understanding of all the issues involved in immunization uptake and delivery, research with other caregivers, such as the fathers, and with health professionals is also required. This will provide further insight into the factors that they believe influence immunization uptake and provide a more comprehensive overview of the problem.

\section{Acknowledgements}

The first author would like to thank First Nations and Inuit Health Branch, Health Canada, for providing the funding for this research.

\section{References}

Abbotts B. \& Osborn L.M. (1993) Immunization status and reasons for immunization delay among children using public health immunization clinics. American Journal of Disease of Children 147, 965-968.

Bennett P. \& Smith C. (1992) Parents attitudinal and social influences on childhood vaccination. Health Education Research 7, 341-348.

Brink P.J. (1989) Exploratory designs. In Advanced Design in Nursing Research (Brink P.J. \& Wood M.J. eds). Sage, Newbury Park, CA, pp. 141-160.

Bruneau A. \& Duchesne C. (2000) Outbreak of mumps, Montreal, October 1998 to March 1999 - with a particular focus on a school. Canada Communicable Disease Report 26, 69-71.

Buchanan N. \& Spencer R. (1983) Immunization non-compliance: time for action. The Medical Journal of Australia 2, 361-362.

Burnard P. (1991) A method of analysing interview transcripts in qualitative research. Nurse Education Today 11, 461-466.

Centers for Disease Control and Prevention (1999a) Epidemiology and Prevention of Vaccine-Preventable Diseases. Department of Health \& Human Services, Atlanta.

Centers for Disease Control and Prevention (1999b) Ten great public health achievements - United States, 1900-1999. Morbidity and Mortality Weekly Report 48, 241-248.

Chen R.T. \& DeStefano F. (1998) Vaccine adverse events: causal or coincidental? The Lancet 351, 611-612.

Dietz V.J., Zell E.R. \& Stevenson J. (1993) Defining delayed immunization. The Pediatric Infectious Disease Journal 12, 353-354.

First Nations and Inuit Health Programs (1999) A Second Diagnostic on the Health of First Nations and Inuit People in Canada. Author, Ottawa, Canada.

Gangarosa E.J., Galazka A.M., Wolfe C.R., Phillips L.M., Gangarosa R.E., MillerE. \& Chen R.T. (1998) Impact of anti-vaccine movements on pertussis control: the untold story. The Lancet 351, 356-361.

Gindler J.S., Cutts F.T., Barnett-Antinori M.E., Zell E.R., Swint E.B., Hadler S.C. \& Rullan J.V. (1993) Successes and failures in vaccine delivery: evaluation of the immunization delivery system in Puerto Rico. Pediatrics 91, 315-320. 
Guba E.G. \& Lincoln Y.S. (1989) Fourth Generation Evaluation. Sage, Newbury Park, CA.

Holt E., Guyer B., Hughart N., Keane V., Vivier P., Ross A. \& Strobino D. (1996) The contribution of missed opportunities to childhood underimmunization in Baltimore. Pediatrics 97, 474-480.

Houseman C., Butterfoss F.D., Morrow A.L. \& Rosenthal J. (1997) Focus groups among public, military, and private sector mothers: insights to improve the immunization process. Public Health Nursing 14, 235-243.

Hutchins S.S., Escolan J., Markowitz L.E., Hawkins C., Kimbler A., Morgan R.A., Preblud S.R. \& Orenstein W.A. (1989) Measles outbreak among unvaccinated preschool-aged children: opportunities missed by health care providers to administer measles vaccine. Pediatrics 83, 369-374.

Keane V., Stanton B., Horton L., Aronson R., Galbraith J. \& Hughart N. (1993) Perceptions of vaccine efficacy, illness, and health among inner-city parents. Clinical Pediatrics 32, 2-7.

Klein N., Morgan K. \& Wansbrough-Jones M.H. (1989) Parent's beliefs about vaccination: the continuing propagation of false contraindications. British Medical Journal 298, 1687.

Lannon C., Brack V., Stuart J., Caplow M., McNeill A., Bordley W.C. \& Margolis P. (1995) What mothers say about why poor children fall behind on immunizations. A summary of focus groups in North Carolina. Archives of Pediatrics and Adolescent Medicine 149, 1070-1075.

Levy R. \& Hollan D. (1998) Person-centered interviewing and observation. In Handbook of Methods in Cultural Anthropology (Russell Bernard H. ed.), Altamira Press, Walnut Creek, CA, pp. 333-364.

Lincoln Y.S. \& Guba E.G. (1985) Naturalistic Inquiry. Sage, Beverly Hills, CA.

Loevinsohn B.P. (1989) Missed opportunities for immunization during visits for curative care: practical reasons for their occurrence. American Journal of Tropical Medicine and Hygiene 4, 255-258.

MacMillan H.L., MacMillan A.B., Offord D.R. \& Dingle J.L. (1996) Aboriginal health. Canadian Medical Association Journal 155, 1569-1578.

McConnochie K.M. \& Roghmann K.J. (1992) Immunization opportunities missed among urban poor children. Pediatrics 89, 1019-1026.

McCormick L.K., Bartholomew L.K., Lewis M.J., Brown M.W. \& Hanson I.C. (1997) Parental perceptions of barriers to childhood immunizations: Results of focus groups conducted in an urban population. Health Education Research 12, 355-362.

Morrow A.L., Rosenthal J., Lakkis H.D., Bowers J.C., Butterfoss F.D., Crews C. \& Sirotkin B. (1998) A Population-based study of access to immunization among urban Virginia children served by public, private, and military health care systems. Pediatrics 101, e5.

Morse J.M. \& Field P.A. (1995) Qualitative Research Methods for Health Professionals. Sage, London.

National Advisory Committee on Immunization (1997) Guidelines for Childhood Immunization Practices. Canada Communicable Disease Weekly Report 23 (ACS-6), 1-5.

National Advisory Committee on Immunization (1998) Canadian Immunization Guide, 5th edn. Health Canada, Ottawa.
New S.J. \& Senior M.L. (1991) 'I don't believe in needles': Qualitative aspects of a study into the uptake of infant immunisation in two English health authorities. Social Science and Medicine 4, 509-518.

Postl B. \& Moffatt M. (1988) The health of Canada's Native people: an overview. Canadian Family Physician 34, 2413-2419.

Pruitt R.H., Kline P.M. \& Kovaz R.B. (1995) Perceived barriers to childhood immunization among rural populations. Journal of Community Health Nursing 12, 65-72.

Roden J. (1992) Child immunisation levels in Sydney's Western Metropolis Region: Parental attitudes and nurses' roles. The Australian Journal of Advanced Nursing 9, 18-24.

Sabnis S.S., Pomeranz A.J., Lye P.S. \& Amateau M.M. (1998) Do missed opportunities stay missed? A 6-month follow-up of missed vaccine opportunities in inner city Milwaukee children. Pediatrics 101, E5.

Salsberry P.J., Nickel J.T. \& Mitch R. (1993) Why aren't preschoolers immunized? A comparison of parents' and providers' perceptions of the barriers to immunizations. Journal of Community Health Nursing 10, 213-224.

Salsberry P.J., Nickel J.T. \& Mitch R. (1994) Immunization status of 2-year-olds in middle/upper- and lower-income populations: a community survey. Public Health Nursing 11, 17-23.

Salsberry P.J., Nickel J.T. \& Mitch R. (1995) Missed opportunities to immunize preschoolers. Applied Nursing Research 8, 56-60.

Sandelowski M. (1986) The problem of rigor in qualitative research. Advances in Nursing Science 8, 27-37.

Sandelowski M. (2000) Whatever happened to qualitative description? Research in Nursing and Health 23, 334-340.

Santoli J.M., Szilagyi P.G. \& Rodewald L.E. (1998) Barriers to immunization and missed opportunities. Pediatric Annals 27, 366374.

Statistics Canada (1996) Population by Aboriginal Groups. Author, Ottawa. Available at http://www.statcan.ca/english/census96/ jan13/can.pdf.AccessedMay2002.

Szilagyi P.G., Rodewald L.E., Humiston S.G., Raubertas R.F., Cove L.A., Doane C.B., Lind P.H., Tobin M.S., Roghmann K.J. \& Hall C.B. (1993) Missed opportunities for childhood vaccinations in office practices and the effect on vaccination status. Pediatrics 91, 1-7.

Webb C. (1999) Analysing qualitative data: computerized and other approaches. Journal of Advanced Nursing 29, 323-330.

Weese C.B. \& Krauss M.R. (1995) A 'barrier-free' health care system does not ensure adequate vaccination of 2-year-old children. Archives of Pediatrics and Adolescent Medicine 149, 1130-1135.

White G.E. \& Thomson A.N. (1995) 'As every good mother should'. Childhood immunization in New Zealand: a qualitative study. Health and Social Care 3, 73-82.

Young T.K. (1979) Changing patterns of health and sickness among the Cree-Ojibwa of Northwestern Ontario. Medical Anthropology 3, 191-223.

Young T.K. (1988) Health Care and Cultural Change: The Indian Experience in the Central Subarctic. University of Toronto, Toronto.

Young T.K. (1990) From medicine men to medicine chest: Indian health care in Canada. Annals RCPSC 23, 247-251.

Young T.K. (1994) The Health of Native Americans: Toward a Biocultural Epidemiology. Oxford University Press, New York. 


\section{Author Query Form}

\section{Journal: $\quad$ JAN}

Article: $\quad 2507$

Dear Author,

During the copy-editing of your paper, the following queries arose. Please respond to these by marking up your proofs with the necessary changes/additions. Please write your answers on the query sheet if there is insufficient space on the page proofs. Please write clearly and follow the conventions shown on the attached corrections sheet. If returning the proof by fax do not write too close to the paper's edge. Please remember that illegible mark-ups may delay publication.

Many thanks for your assistance.

\begin{tabular}{|c|c|c|}
\hline Query reference & Query & Remarks \\
\hline 1 & $\begin{array}{l}\text { Lannon } 1995 \text { has been changed to Lannon et al. } 1995 \text { so that this citation } \\
\text { matches the list }\end{array}$ & \\
\hline 2 & $\begin{array}{l}\text { Houseman } 1997 \text { has been changed to Houseman et al. } 1997 \text { so that this } \\
\text { citation matches the list }\end{array}$ & \\
\hline 3 & $\begin{array}{l}\text { McCormick } 1997 \text { has been changed to McCormick et al. } 1997 \text { so that this } \\
\text { citation matches the list }\end{array}$ & \\
\hline
\end{tabular}




\section{Please correct and return this set}

Any errors in this proof which have been noticed by the printer's reader have been marked in green. If you see any more printer's errors, please mark them in red: there is no charge for correcting these mistakes. For your own alterations, please use black or blue or any colour other than green or red. Please use the proof correction marks shown below for all alterations and corrections.

\begin{tabular}{|c|c|c|}
\hline Instruction to printer & Textual mark & Marginal mark \\
\hline Leave unchanged & ... under matter to remain & Stet \\
\hline $\begin{array}{l}\text { Insert in text the matter } \\
\text { indicated in the margin }\end{array}$ & $h$ & $\begin{array}{l}\text { New matter followed by } \\
\boldsymbol{h}\end{array}$ \\
\hline Delete & $\mapsto$ through matter to be deleted & d] \\
\hline Delete and close up & E through matter to be deleted & व \\
\hline $\begin{array}{l}\text { Substitute character or } \\
\text { substitute part of one or } \\
\text { more word(s) }\end{array}$ & $\begin{array}{l}/ \text { through letter or } \mapsto \text { through } \\
\text { word }\end{array}$ & N̈ew letter or new word \\
\hline Change to italics & - under matter to be changed & لب \\
\hline Change to capitals & $\equiv$ under matter to be changed & $\equiv$ \\
\hline Change to $s$ & $=$ under matter to be changed & $=$ \\
\hline Change to bold type & m under matter to be changed & $m$ \\
\hline Change to bold italic & $=$ under matter to be changed & \\
\hline Change to lower case & Encircle matter to be changed & $\#$ \\
\hline Change italic to upright type & (As above) & 4 \\
\hline Insert 'superior' character & $\begin{array}{l}/ \text { through character or } \wedge \text { where } \\
\text { required }\end{array}$ & $\begin{array}{l}y \text { under character } \\
\text { e.g. } \$\end{array}$ \\
\hline Insert 'inferior' character & (As above) & L over character e.g. $\frac{h}{2}$ \\
\hline Insert full stop & (As ab & 0 \\
\hline Insert comma & (As above) & , \\
\hline Insert single quotation marks & (As above) & $y$ and/or $y$ \\
\hline $\begin{array}{l}\text { Insert double quotation } \\
\text { marks }\end{array}$ & (As above) & "y and/or $y$ \\
\hline Insert hyphen & (As abo & (بy \\
\hline Start new paragraph & $\sqrt{-10}$ & 5 \\
\hline No new paragraph & 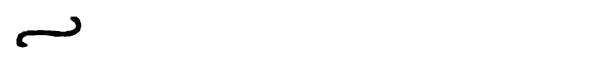 & 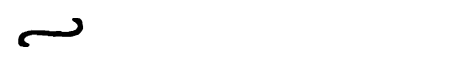 \\
\hline Transpose & $山$ & $\sqrt{-1}$ \\
\hline Close up & linking こ & $=$ \\
\hline Insert space between letters & $h$ between letters a & $\#$ \\
\hline Insert space between words & $\boldsymbol{h}$ between words affected & \# \\
\hline Reduce space between letters & $\uparrow$ between letters affected & $T$ \\
\hline Reduce space between words & $\tau$ between words affected & \\
\hline
\end{tabular}

